\title{
Activity of the Principal Cells of the Olfactory Bulb Promotes a Structural Dynamic on the Distal Dendrites of Immature Adult-Born Granule Cells via Activation of NMDA Receptors
}

\author{
Vincent Breton-Provencher, ${ }^{1}$ Daniel Coté, ${ }^{1,2}$ and Armen Saghatelyan ${ }^{1,3}$ \\ ${ }^{1}$ Cellular Neurobiology Unit, Centre de recherche de l'Institut Universitaire en Santé Mentale de Québec, Quebec City, Quebec, Canada G1J 2G3, 2Centre for \\ Optics, Photonics, and Lasers, Université Laval, Quebec City, Quebec, Canada G1K 7P4, and ${ }^{3}$ Department of Psychiatry and Neuroscience, Université Laval, \\ Quebec City, Quebec, Canada G1K 7P4
}

\begin{abstract}
The adult olfactory bulb is continuously supplied with neuronal precursors that differentiate into granule and periglomerular cells. Little is known about the structural dynamic of adult-born granule cells (GCs) at their different maturational stages, the mechanisms controlling the integration of new neurons into the pre-existing neuronal circuitry, or the role of principal cell activity in these processes. We used two-photon time-lapse imaging to reveal a high level of filopodia formation and retraction on the distal dendrites of adult-born GCs at their early maturational stages. This dynamic decreased as the adult-born interneurons matured. Filopodia formation/retraction on the dendrites of adult-born GCs at the early maturational stages depended on the activation of NMDA receptors (NMDARs). The stimulation of mitral cells using a pattern that mimics activity of these principal neurons to odor presentation promotes the NMDAR-dependent filopodia dynamic of adult-born GCs during their early but not late maturational stages. Moreover, NMDA iontophoresis was sufficient to induce the formation of new filopodia on the distal dendrites of immature adult-born GCs. The maturation of adult-born interneurons was accompanied by a progressive hyperpolarization of the membrane potential and an increased $\mathrm{Mg}^{2+}$ block of NMDARs. Decreasing the extracellular $\mathrm{Mg}^{2+}$ concentration led to filopodia formation on the dendrites of mature adult-born GCs following NMDA iontophoresis. Our findings reveal an increased structural dynamic of adult-born GCs during the early stages of their integration into the mouse bulbar circuitry and highlight a critical period during which the principal cells' activity influences filopodia formation/retraction on the dendrites of interneurons.
\end{abstract}

Key words: adult neurogenesis; granule cells; maturation; NMDA; olfactory bulb; two-photon imaging

\section{Introduction}

The adult olfactory bulb (OB) displays an unusual form of plasticity, with thousands of new neurons being added to the bulbar network on a daily basis (Alvarez-Buylla and Garcia-Verdugo, 2002; Breton-Provencher and Saghatelyan, 2012). Neuronal precursors are produced in the subventricular zone (SVZ) and migrate long distances in the rostral migratory stream (RMS) before reaching the $\mathrm{OB}$, where they differentiate into periglomerular and granule cells (GCs). In the OB, some of these adult-born GCs integrate into the operational neuronal network by establishing dendrodendritic synapses with mitral/tufted cells, the principal

Received July 16, 2013; revised Dec. 16, 2013; accepted Dec. 19, 2013.

Author contributions: V.B.-P. and A.S. designed research; V.B.-P. performed research; D.C. contributed unpublished reagents/analytic tools; V.B.-P. and A.S. analyzed data; V.B.-P. and A.S. wrote the paper.

This work was funded by an operating grant from the National Science and Engineering Research Council of Canada to A.S., V.B.-P. was supported by a PhD fellowship from the Fonds de recherche en santé du Québec and a training grant in neurophotonics from the Canadian Institutes of Health Research. D.C. holds a Canada Research Chair in biophotonics, and A.S. holds a Canada Research Chair in postnatal neurogenesis.

The authors declare no competing financial interests.

Correspondence should be addressed to Dr Armen Saghatelyan, Centre de recherche de I'Institut Universitaire en Santé Mentale de Québec, Université Laval, 2601 Chemin de la Canardière, Quebec City, QC, Canada G1J 2G3. E-mail: armen.saghatelyan@crulrg.ulaval.ca.

DOI:10.1523/JNEUROSCI.3013-13.2014

Copyright $\odot 2014$ the authors $\quad 0270-6474 / 14 / 341748-12 \$ 15.00 / 0$ neurons (Alvarez-Buylla and Garcia-Verdugo, 2002; Lledo et al., 2006). Although the morphological and electrophysiological profiles of adult-born neuron development in the OB have been determined (Petreanu and Alvarez-Buylla, 2002; Belluzzi et al., 2003; Carleton et al., 2003), it remains unclear how these cells form synapses in the bulbar network. It has recently been shown that adult-born neurons form output dendrodendritic synapses on their distal dendrites after receiving excitatory synaptic inputs on their soma and basal dendrites (Whitman and Greer, 2007; Kelsch et al., 2008) and that the GABAergic input predominates during the early stages of adult-born GC maturation (Panzanelli et al., 2009; Pallotto et al., 2012). These morphological analyses were performed in fixed $\mathrm{OB}$ sections and did not reveal the dynamic changes occurring during the formation of dendrodendritic synapses. In addition, little is known about the molecular cues that trigger the formation of initial contacts between principal neurons and adult-born GCs and how mitral/tufted cell activity influences these processes.

The few in vivo long-term studies of spine formation on adultborn GCs have shown that there is a high turnover of dendritic spines 2 weeks after the integration of new interneurons (Mizrahi, 2007; Livneh et al., 2009; Kopel et al., 2012). This suggests that the formation/retraction of spines occurs within hours and 
that it lasts for months after the integration of the adult-born GCs. However, the slow sampling rate and the difficulty in assessing the molecular cues that regulate spine formation in in vivo studies, have prevented the investigation of the dynamic and molecular factors involved in the initial stages of spine formation by adult-born GCs.

In the present study, we performed time-lapse two-photon imaging in acute slices of the $\mathrm{OB}$ to reveal the structural dynamic of adult-born GCs at their different maturational stages and to directly assess the role of principal cell activity in the integration of new neurons. We detected a high rate of filopodia formation/ retraction on the distal dendrites of immature adult-born GCs that decreases with cell maturation. We also showed that principal cell activity regulates the filopodia dynamic during the early but not the late maturational stages through the activation of NMDA receptors (NMDARs) on adult-born GC dendrites. Our results provide a basis for understanding the mechanisms involved in integrating adult-born GCs into the pre-existing bulbar network.

\section{Materials and Methods}

Animals. Adult ( $>2$ months old) male C57BL/6 mice (Charles River) were used for all the experiments, which were performed in accordance with the Canadian Guide for the Care and Use of Laboratory Animals and were approved by the Université Laval Animal Protection Committee. The mice were kept on a $12 \mathrm{~h}$ light/dark cycle at a constant temperature $\left(22^{\circ} \mathrm{C}\right)$ with food and water ad libitum.

Stereotaxic injections. A GFP-encoding lentivirus was stereotaxically injected into the RMS of both brain hemispheres to label the adultborn GCs. The lentivirus was purchased from either the Platform for Cellular Imaging of the Centre de Recherche de l'Institut Universitaire en Santé Mentale de Québec or the University of North Carolina Vector Core Facility. The following coordinates were used for the stereotaxic injections (with respect to the bregma): anterior-posterior: $2.55 \mathrm{~mm}$, medial-lateral: $\pm 0.82 \mathrm{~mm}$, and dorsal-ventral: 3.15 $\mathrm{mm}$. After the injection, mice were returned to their cages for various times $[7,14,28,42$, and $\geq 77$ (77-163) days postinjection; DPI]. For the maturational stages $\geq 14 \mathrm{DPI}$, we consistently examined the number of GFP-labeled neuroblasts in the RMS of the OB $\left(\mathrm{RMS}_{\mathrm{OB}}\right)$ to ascertain that lentivirus injections in the RMS did not label a significant proportion of the stem cells. We detected a negligible number of $\mathrm{GFP}+$ neuroblasts in the $\mathrm{RMS}_{\mathrm{OB}}(3.2 \pm 2.0 \%, n=3$ animals at 14 DPI; $3.8 \pm 0.9 \%, n=5$ animals at 28 DPI; $3.3 \pm 0.9 \% n=4$ animals at 42 DPI; based on DAPI staining), indicating that our method provided an accurate assessment of the age of adult-born neurons.

Time-lapse two-photon imaging. One week to 6 months after the lentivirus injections, we deeply anesthetized the mice and transcardially perfused them with ice-cold oxygenated artificial CSF (ACSF) containing the following (in $\mathrm{mm}$ ): 250 sucrose, $3 \mathrm{KCl}, 0.5 \mathrm{CaCl}_{2}, 3 \mathrm{MgCl}_{2}, 25$ $\mathrm{NaHCO}_{3}, 1.25 \mathrm{NaH}_{2} \mathrm{PO}_{4}$, and 10 glucose. The OB was then quickly removed, and horizontal $250-300 \mu \mathrm{m}$ slices were prepared using a vibrating blade microtome (HM 650V Thermo Scientific). The slices were transferred into oxygenated ACSF containing the following (in mM): 124 $\mathrm{NaCl}, 3 \mathrm{KCl}, 2 \mathrm{CaCl}_{2}, 1.3 \mathrm{MgCl}_{2}, 25 \mathrm{NaHCO}_{3}, 1.25 \mathrm{NaH}_{2} \mathrm{PO}_{4}$, and 10 glucose. The temperature of the ACSF was maintained at $32^{\circ} \mathrm{C}$ for the duration of the experiment.

For the time-lapse imaging experiments, a slice was placed in a perfusion chamber equipped with a temperature controller (Warner Instrument), and a custom-made anchor was placed on top of the slice to prevent drifting during image acquisition. The slice was first inspected using a wide-field epifluorescence microscope to detect GFP+ cell dendrites and spines. We only used well-preserved GCs with distal dendrites located at least $40 \mu \mathrm{m}$ deep in the slice for the time-lapse imaging. $z$-Stack images were acquired using a custom-made two-photon microscope (modified FV300 system from Olympus). The thickness of the $z$-stacks varied from 25 to $70 \mu \mathrm{m}$. We performed a $z$-stack every 5 min to image the dynamic on the dendrites of adult-born GCs. We used a tunable
Ti:Sapphire femtosecond laser (Coherent) at an excitation wavelength of $900 \mathrm{~nm}$. The power of the excitation light exiting the objective was $\sim 10-20 \mathrm{~mW}$. To ascertain that at this laser power there was no photobleaching, we measured the GFP fluorescence intensity in the thin filopodia that remained stable throughout imaging session. Our analysis demonstrated a stable level of GFP fluorescence (data not shown) indicating for the absence of photobleaching. Fluoview 5.0 software was used to acquire the images. A $60 \times$ water-immersion objective optimized for infrared light (LUMPlanFl/IR 60× NA: 0.90, Olympus) was used for the time-lapse experiments.

Filopodia dynamic analysis. Time-lapse images were analyzed using a custom-made MATLAB program (version R2010a, MathWorks). A maximum projection image of each time point was created. The drift between the time points was then corrected using an algorithm based on cross-correlation. The initial $512 \times 512$ pixel images were cropped to $200 \times 200$ pixels $(\sim 40 \times 40 \mu \mathrm{m})$ to facilitate visualization of the dynamic. We also used a special overlay of each time point to facilitate quantification of forming and retracting filopodia. The current and previous time points were false colored in green and red, respectively, allowing stable structures to be visualized in yellow, forming ones in green, and retracting ones in red.

To evaluate the degree of morphological reorganization at each morphological stage, we calculated the dynamic index, which represents the number of forming/retracting filopodia per $\mu \mathrm{m}$ length of dendrite during $1 \mathrm{~h}$ of recording. The dynamic index was obtained by manually counting forming/retracting filopodia on the dendrites of the adult-born GCs during the acquisition period. The lifetime of the filopodia was determined by tracking each filopodia manually using the MTrackJ plugin (developed by Dr. Erik Meijering at the Biomedical Imaging Group Rotterdam, University Medical Center Rotterdam, The Netherlands) for ImageJ. The resolution of the lifetime measurement was limited by the sampling rate $(5 \mathrm{~min})$ and the length of the time-lapse acquisition (45 min, 10 time points).

Lateral olfactory tract stimulation. To assess the role of mitral cell activity in the filopodia dynamic of adult-born GCs, we stimulated the lateral olfactory tract (LOT) where all the axons of these neurons converge. For these experiments, we used acute horizontal slices of a ventral OB that had a well-preserved LOT. To ascertain that the imaged adult-born GCs dendrites were located in the region activated by the electrical stimulation of the LOT, we also recorded local field potentials from that area. The stimulating and recording pipettes were both filled with ACSF, and their resistance ranged from 3 to 5 $\mathrm{M} \Omega$. We introduced the stimulating pipette into the LOT and positioned the recording pipette in the external plexiform layer (EPL) region close to the adult-born GC being imaged. We first gave a single $0.2 \mathrm{~ms}$ pulse at $\sim 100 \mu \mathrm{A}$ using an A360 stimulus isolator (World Precision Instruments) controlled by a Digidata 1440A (Molecular Devices). We recorded the response in the EPL using a Multiclamp 700B amplifier (Molecular Devices). The initial pulse allowed us to ascertain that the distal dendrites of the adult-born GC being imaged were located in the region activated by the electrical stimulation of the LOT. We positioned the stimulating pipette as far as possible from the imaging region to avoid directly stimulating the adult-born GC. After detecting a synaptic response in the EPL, we imaged the dynamic of the adult-born GC for a baseline (BL) period once every 5 min for 45 min (10 time points). The BL period was followed by another imaging session during which we applied a specific stimulation pattern to the LOT at each time point for an additional $45 \mathrm{~min}$. To activate mitral cells, we used a stimulation pattern ( 5 brief $0.1 \mathrm{~ms}$ pulses at $25 \mathrm{~Hz}$ repeated 60 times every $500 \mathrm{~ms}$ ) that mimicked the response of these principal neurons to odor presentation (Cang and Isaacson, 2003). In addition to this stimulation paradigm hereinafter called "pattern stimulation" we also used a random stimulation protocol that consisted of the same number of electrical pulses but spaced randomly during the $30 \mathrm{~s}$ period. The random stimulation protocol was created using a MATLAB program.

In some experiments, to investigate the role of the NMDA and AMPA receptors in the filopodia dynamic of adult-born GCs, we added a third imaging session during which we performed the LOT stimulation in the 
presence of $50 \mu \mathrm{m}$ bath applied APV (NMDA receptor antagonist), $25 \mu \mathrm{M}$ NBQX (AMPA receptor agonist), or $25 \mu \mathrm{M}$ MK801 (usedependent NMDA receptor antagonist; all from Ascent). MK-801 was bath applied during at least $10 \mathrm{~min}$ without any electrical stimulation to allow antagonist to be well infused into the $\mathrm{OB}$ slice before resuming the LOT stimulation. For analysis of MK-801 data only the last 25 min of 45-min-long imaging session were taken.

Iontophoresis. We used iontophoresis to locally apply NMDA to the distal dendrites of adult-born GCs and assess changes in the filopodia dynamic. We first recorded the BL dynamic of the adult-born GC for $45 \mathrm{~min}$. We then placed a pipette filled with NMDA (100 mm diluted in ACSF) at a distance of $4.8 \pm 0.2$ $\mu \mathrm{m}$ (average value calculated for the 35 cells used in these experiments) from the dendrites of interest. In all experiments, $10 \mu \mathrm{M}$ AlexaFluor 594 was added to the pipette content to visualize its position precisely. We applied one $2 \mathrm{~ms}$ pulse of negative current (ranging from 150 to $250 \mathrm{nA}$ ) at the beginning of the second period of time-lapse acquisition using an ION100 (Dagan) apparatus. The dynamic indexes for the iontophoresis experiments were calculated for a $20 \times 20 \mu \mathrm{m}$ region centered around the iontophoresis pipette. We calculated filopodia dynamic on the remote positions, on the dendritic segments of adult-born GC located $>20 \mu \mathrm{m}$ from the pipette. We also used the application of ACSF as a control. To ascertain that the iontophoresis currents were efficient, we performed whole-cell recordings of the GCs and obtained electrophysiological responses following the iontophoresis of NMDA using the same amplitude of iontophoresis currents as those used in imaging experiments (data not shown). To assess the role of a magnesium block in the NMDA-induced filopodia dynamic at 14 DPI, we also performed iontophoresis experiments using ACSF containing 0.65 instead of $1.3 \mathrm{~mm} \mathrm{MgCl}_{2}$.

Patch-clamp recordings. We recorded the membrane properties of the GCs at different maturational stages using the whole-cell configuration. We filled borosilicate glass pipettes (resistance ranging from 7 to $9 \mathrm{M} \Omega$ ) with the following intracellular solution (in $\mathrm{mM}$ ): 130 K-methylsulfate, 10 HEPES, $6 \mathrm{KCl}, 2 \mathrm{Mg}$-ATP, 3 Na-GTP, 10 Na-phosphocreatine, and 2 ascorbate. The recordings were performed using a Multiclamp 700B amplifier connected to a Digidata 1440A (Molecular Devices). We estimated the resting membrane potential and passive membrane properties immediately after the opening of the membrane. The spontaneous excitatory post-synaptic currents (sEPSCs) were recorded by clamping the cell at $-60 \mathrm{mV}$ in the presence of bicuculline methochloride $(50 \mu \mathrm{M}$; Ascent) to block the $\mathrm{GABA}_{\mathrm{A}}$-mediated currents. Miniature EPSCs (mEPSCs) were isolated by adding tetrodotoxin $(1 \mu \mathrm{M})$ to block voltagegated sodium channels. The traces were analyzed using the MiniAnalysis software (Synaptosoft).

Statistical analysis. All values are expressed as mean \pm SEM. The normality of the samples was assessed using a Lilliefors test. Statistical

E
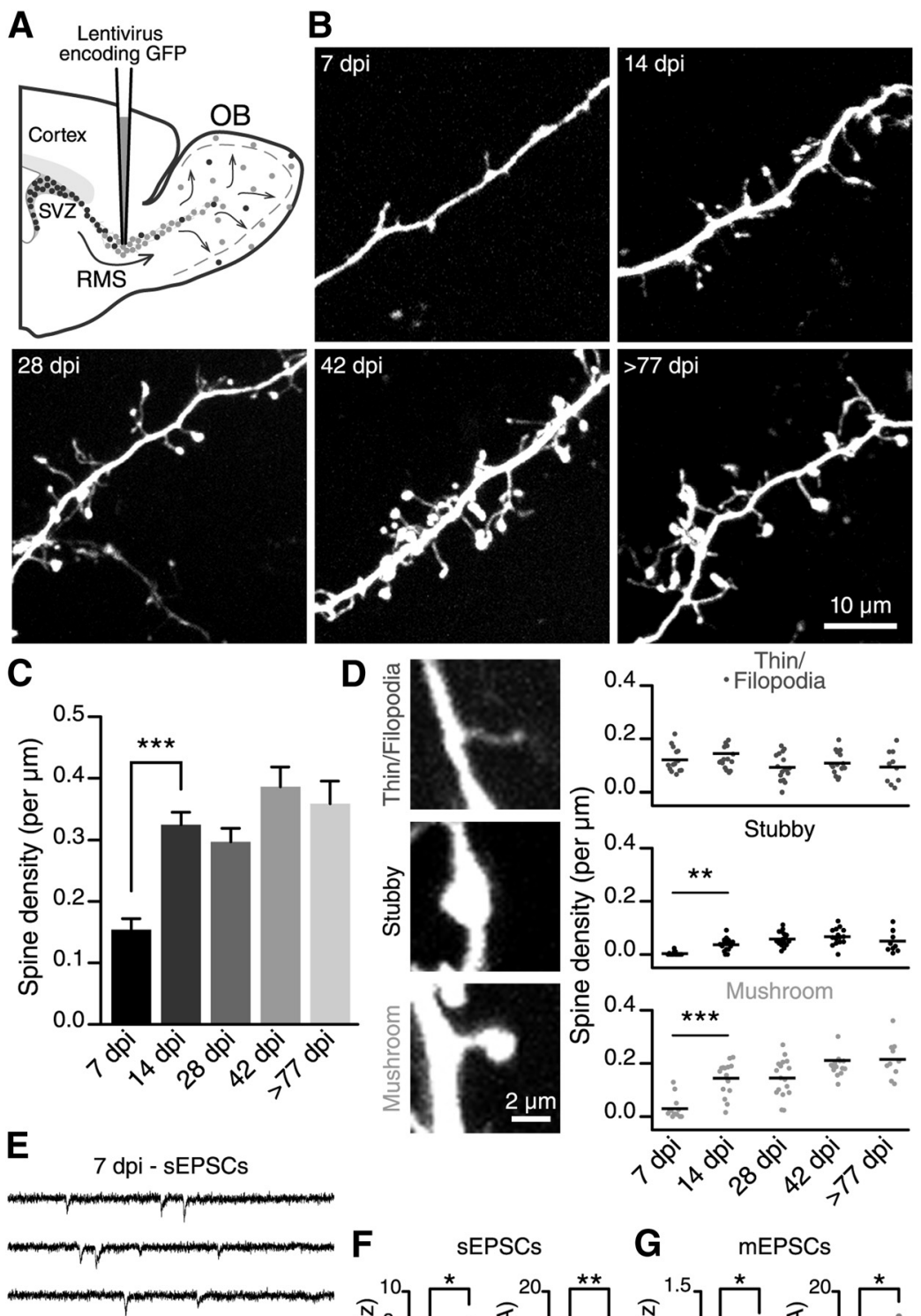

14 dpi - sEPSCs
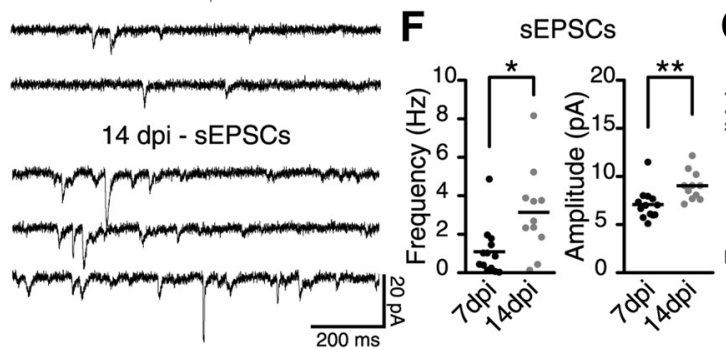

G

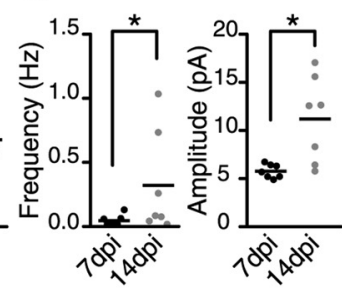

Figure 1. Spine density increases on the distal dendrites of adult-born GCs during their maturation. $\boldsymbol{A}, \mathrm{A}$ schematic drawing illustrating the methodology for labeling adult-born GCs at different maturational stages. Adult 2- to 3-month-old C57BL/6 mice were stereotaxically injected in the RMS with a GFP-encoding lentivirus. $\boldsymbol{B}$, Representative images of the distal dendrites of adult-born GCs at different maturational stages based on the number of DPI. C, Quantification of the spine density (number of spines per dendrite length) on the distal dendrites of adult-born $\mathrm{GCs}$ at each developmental stage. A significant increase in spine density from 7 to $14 \mathrm{DPI}$ can be seen. $\boldsymbol{D}$, Left, Representative images are shown for each class of spine used for the analysis. Right, Density of thin filopodia-like protrusions and stubby and mushroom spines. The main increase in density for stubby and mushroom spine classes occurred between the 7 and $14 \mathrm{DPI}$ maturational stages; $n=14$, $16,17,15$, and 10 cells for the 7, 14, 28, 42, and $\geq 77$ DPI conditions, respectively. ${ }^{* *} p<0.01$ and ${ }^{* * *} p<0.001$ using a one-way ANOVA with Tukey's post hoc test. $E$, Example traces for the SEPSCs recorded from adult-born GCs at 7 and $14 \mathrm{DPI}$. $\boldsymbol{F}$, Frequency and amplitude of the sEPSCs recorded at $7(n=13)$ and $14(n=11)$ DPI. ${ }^{*} p<0.05$ and ${ }^{* *} p<0.01$ using Student's $t$ test. G, Frequency and amplitude of the mEPSCs recorded at $7(n=7)$ and $14(n=7)$ DPI. ${ }^{*} p<0.05$ using a Mann-Whitney $U$ test for frequency and Student's $t$ test for the amplitude analysis, respectively.

significance was tested using a paired Student's $t$ test for the experiments involving the time-lapse imaging of the same dendrites in different conditions, and a one-way ANOVA with Tukey's post hoc test to compare the groups at different times after injection $(7,14,28,42$, 
$\geq 77$ DPI). We used a Mann-Whitney $U$ test when the sample was not following a normal distribution (Fig. $1 G$; frequency analysis). The level of significance were as follows: ${ }^{\star} p<0.05,{ }^{\star *} p<0.01$, and ${ }^{\star * *} p<$ 0.001 .

\section{Results \\ Spine density increases during the maturation of adult-born GCs in the OB}

To establish the profile of synaptic development of adult-born GCs, we labeled neuronal precursors by stereotaxically injecting a GFP-encoding lentivirus into the RMS and analyzed the spine density of new neurons in acute OB slices (Fig. 1A). We imaged adult-born GCs at 7,14, 28, 42, and $\geq 77$ DPI (Fig. 1B). Our two-photon imaging experiments using living tissues showed that the maturation of adult-born cells is accompanied by a gradual increase in the number of spines (Fig. $1 B, C$ ). The spine density increased rapidly from $7 \mathrm{DPI}(0.15 \pm 0.02$ spines per $\mu \mathrm{m}, n=$ 14 cells $)$ to $14 \mathrm{DPI}(0.33 \pm 0.02$ spines per $\mu \mathrm{m}, n=16$ cells $)$ and remained stable thereafter at $\sim 0.34 \pm 0.01$ spines per $\mu \mathrm{m}$ (Fig. $1 C)$. These results are in line with our analysis of adult-born GCs maturation in the fixed tissue that showed the same pattern of spine density increase (data not shown) and are in agreement with previous observations (Petreanu and Alvarez-Buylla, 2002; Whitman and Greer, 2007; Panzanelli et al., 2009). At the initial stage of maturation (7 DPI), we observed only a few spines with well-defined heads. Most of the dendritic protrusions were thin, filopodia-like structures (Fig. $1 B, D$ ). The number of apparently mature spines with well defined necks and heads (mushroom spines) or heads (stubby spines) had increased by 14 DPI (Fig. $1 B, D)$. The quantification of these different classes revealed two trends. First, the density of stubby and mushroom spines on adult-born GCs increased during the first 2 weeks of integration and reached a plateau thereafter (for stubby spines: $0.003 \pm 0.002$ per $\mu \mathrm{m}$ at $7 \mathrm{DPI}, 0.037 \pm 0.006$ per $\mu \mathrm{m}$ at $14 \mathrm{DPI}, 0.058 \pm 0.006$ per $\mu \mathrm{m}$ at $28 \mathrm{DPI}, 0.067 \pm 0.008$ per $\mu \mathrm{m}$ at $42 \mathrm{DPI}$, and $0.05 \pm$ 0.013 per $\mu \mathrm{m}$ at $\geq 77 \mathrm{DPI}$; for mushroom spines: $0.030 \pm 0.011$ per $\mu \mathrm{m}$ at $7 \mathrm{DPI}, 0.144 \pm 0.015$ per $\mu \mathrm{m}$ at $14 \mathrm{DPI}, 0.145 \pm 0.017$ per $\mu \mathrm{m}$ at $28 \mathrm{DPI}, 0.211 \pm 0.021$ per $\mu \mathrm{m}$ at $42 \mathrm{DPI}$, and $0.215 \pm$ 0.022 per $\mu \mathrm{m}$ at $\geq 77 \mathrm{DPI} ; n=14,16,17,15$, and 10 cells for the $7,14,28,42$, and $\geq 77$ DPI conditions, respectively; Fig. 1D). Second, the density of filopodia-like immature spines remained the same throughout the lifetime of adult-born GCs $(0.121 \pm$ 0.012 spines per $\mu \mathrm{m}$ at $7 \mathrm{DPI}, 0.145 \pm 0.021$ spines per $\mu \mathrm{m}$ at 14 DPI, $0.093 \pm 0.012$ spines per $\mu \mathrm{m}$ at $28 \mathrm{DPI}, 0.109 \pm 0.011$ spines per $\mu \mathrm{m}$ at $42 \mathrm{DPI}$, and $0.094 \pm 0.019$ spines per $\mu \mathrm{m}$ at $\geq 77 \mathrm{DPI}$; $n=14,16,17,15$, and 10 cells for the $7,14,28,42$, and $\geq 77$ DPI conditions, respectively; Fig. 1D).

These results indicated that the 7-14 DPI timeframe is a critical period for adult-born GC maturation into the OB. At 7 DPI, GCs mature and start to form synapses with principal neurons. At 14 DPI, GCs appear similar to well matured GCs in the OB (compare the 14 and $\geq 77$ DPI groups; Fig. $1 B, D$ ). To provide a functional assessment of adult-born GCs integration at these maturational stages we performed whole-cell recordings of sEPSC and mEPSCs (Fig. 1E-G). Our recordings performed from adult-born GCs revealed a higher frequency and amplitude of sEPSCs and mEPSCs at 14 DPI compared with 7 DPI (sEPSCs: $1.1 \pm 0.4 \mathrm{~Hz}$ and $7.1 \pm 0.4 \mathrm{pA}$ at $7 \mathrm{DPI}$ and $3.1 \pm 0.7 \mathrm{~Hz}$ and $9.0 \pm$ $0.5 \mathrm{pA}$ at $14 \mathrm{DPI} ; n=13$ and 11 cells, respectively; mEPSCs: $0.05 \pm 0.02 \mathrm{~Hz}$ and $5.8 \pm 0.3 \mathrm{pA}$ at $7 \mathrm{DPI}$ and $0.32 \pm 0.15 \mathrm{~Hz}$ and $11.2 \pm 1.7 \mathrm{pA}$ at $14 \mathrm{DPI} ; n=7$ cells for each condition; Fig. $1 F, G)$. These results showed that the 7-14 DPI period is a critical stage for both maturation and integration of adult-born GCs which is consistent with previous observations showing that 2 weeks after viral labeling in the RMS, adult-born GCs in the OB display the properties of mature neurons (Nissant et al., 2009).

\section{Adult-born GCs integrating the OB display a high level of structural dynamic on their distal dendrites}

To evaluate the degree of structural reorganization at each morphological stage, we performed time-lapse two-photon imaging of adult-born GCs. Our experiments revealed that adult-born GCs display a high level of dynamic on the distal dendrites at an early maturational stage ( $7 \mathrm{DPI}$; Fig. $2 A, B$ ). The predominant structural modification at this maturational stage was the continuous formation/retraction of thin filopodia-like protrusions on the distal dendrites of newborn GCs (Fig. 2A, B). This dynamic decreased at later maturational stages (14 DPI and beyond; Fig. $2 C, D)$. To evaluate the degree of morphological reorganization at each morphological stage, we introduced a quantitative measure called a dynamic index, which represents the number of forming/ retracting filopodia per $\mu \mathrm{m}$ length of dendrite during $1 \mathrm{~h}$ of recording. The dynamic index was high at an early maturational stage ( 7 DPI; $0.39 \pm 0.03, n=14$ cells; Fig. $2 E$ ), which is consistent with the high number of forming/retracting filopodia observed on the dendrites of adult-born neurons at this maturational stage (Fig. $2 F$ ). Interestingly, although the overall number of filopodia on the distal dendrites of adult-born GCs was similar at different maturational stages (Fig. 1D), their dynamic drastically decreased with cell maturation (Fig. 2E). At 14 DPI, the dynamic index had decreased almost threefold $(0.15 \pm$ $0.01, n=16$ cells), followed by an additional twofold drop in the dynamic index at $28 \mathrm{DPI}(0.07 \pm 0.01, n=17$ cells; Fig. $2 E)$. To ascertain that the differences in the dynamic index observed at distinct maturational stages are not influenced by the changes in the overall level of GFP fluorescence across the cell development, we normalized the values of dynamic index of each imaged cell to the level of GFP intensity measured from the dendritic shaft of that neuron. This analysis again revealed a high filopodia dynamic at early maturational stages of adult-born GCs that drastically decreased with cell maturation (Fig. 2E, inset). The decrease in the dynamic at later maturational stages can be attributed to the decline in the number of both forming and retracting filopodia (Fig. 2F). These results suggested that some of the thin filopodia-like structures stabilize at more mature stages of adultborn GCs or that their dynamic occurs over a longer timeframe than the one used in our study (up to $2 \mathrm{~h}$ of imaging).

We next quantified the lifetime of filopodia, which indicated how long filopodia can be observed after their initial formation (Fig. 2G). The quantification of the lifetime of the filopodia at different maturation stages revealed a slighter longer, albeit not significant, lifetime at 14 DPI compared with 7 DPI ( $14 \pm 1 \mathrm{~min}$, $n=13$ cells at $7 \mathrm{DPI}$; and $17 \pm 1 \mathrm{~min}, n=14$ cells at $14 \mathrm{DPI}$; Fig. $2 G)$. The lifetime of the filopodia remained relatively stable at later maturational stages $(17.7 \pm 1.2 \mathrm{~min}, n=15$ cells at $28 \mathrm{DPI}$; $19.5 \pm 1.4 \mathrm{~min}, n=12$ cells at $42 \mathrm{DPI}$; and $18.5 \pm 1.5 \mathrm{~min}, n=6$ cells at $\geq 77$ DPI; Fig. $2 G$ ), with the only significant difference observed between 7 and 42 DPI. Overall, these results showed that adult-born GCs display a high level of dynamic on their dendrites 1 week after arriving in the OB, suggesting that constant morphological reorganization occurs when massive spines and dendrodendritic synapses are being formed. At 14 DPI, adultborn GCs resembled fully mature neurons in terms of spine density and morphology (Fig. 1) and structural dynamic (Fig. 2). We thus chose these two time points for further analysis. 
The filopodia dynamic of adult-born GCs at 7 DPI, but not 14 DPI depends on the activation of NMDARs

The $\mathrm{OB}$ interneurons receive a massive glutamatergic input via dendrodendritic reciprocal synapses with mitral cells, axon collaterals of these principal neurons or centrifugal fibers from the olfactory cortex (Shepherd et al., 2004; Matsutani and Yamamoto, 2008); and electrophysiological recordings from adult-born GCs have shown that neuronal precursors already display extrasynaptic NMDA currents during their migration in the RMS (Platel et al., 2010) and acquire AMPA currents following their arrival in the $\mathrm{OB}$ (Carleton et al., 2003). To test the potential role of spontaneously released glutamate in the BL filopodia dynamic of adult-born GCs at 7 and 14 DPI, we bath applied NMDARs and AMPA receptors (AMPARs) antagonists APV (50 $\mu \mathrm{M})$ and NBQX (25 $\mu \mathrm{M})$, and monitored the filopodia dynamic. Bath application of APV decreased the overall filopodia dynamic on adultborn GCs at 7 DPI $(76.4 \pm 7.1 \%$ of the BL value, $n=11$ cells; Fig. $3 A, C)$, whereas NBQX had no effect at this maturational stage $(93.9 \pm 9.7 \%$ of the BL value, $n=10$ cells; Fig. $3 B, C)$. Interestingly, the effect of APV on the filopodia dynamic on the distal dendrites of GCs disappeared at 14 DPI (91.1 $\pm 10.9 \%, n=12$ cells, and $112.3 \pm 14.6 \%, n=12$ cells, of the $\mathrm{BL}$ value for NBQX and APV, respectively; Fig. 3C). The increased spread of normalized values of dynamic index at $14 \mathrm{DPI}$ (Fig. 3C) is due to the lower BL values of filopodia dynamic at this maturational stage (Fig. 2E). Altogether, these results indicated that NMDARs, but not AMPARs activation in immature adult-born GCs at 7 DPI is required to induce a filopodia dynamic on their distal dendrites. Furthermore, these data, together with analysis of filopodia dynamic at distinct maturational stages of adult-born GCs (Fig. 2), have also shown that reduced BL filopodia dynamic on the dendrites of mature adult-born GCs (14 DPI) cannot be further modulated by NMDAR or AMPAR activation.

The activity of the principal cells influences the filopodia dynamic of adult-born GCs

Adult-born GCs integrate the pre-existing network of the $\mathrm{OB}$ and sensory activity modulates the survival, morphology, and spine number of new interneurons (Rochefort et al., 2002; Saghatelyan et al., 2005; Kelsch et al., 2009; Bastien-Dionne et al., 2010). The mechanisms underlying the sensory activity-induced effects on the morphology and integration of newborn cells are
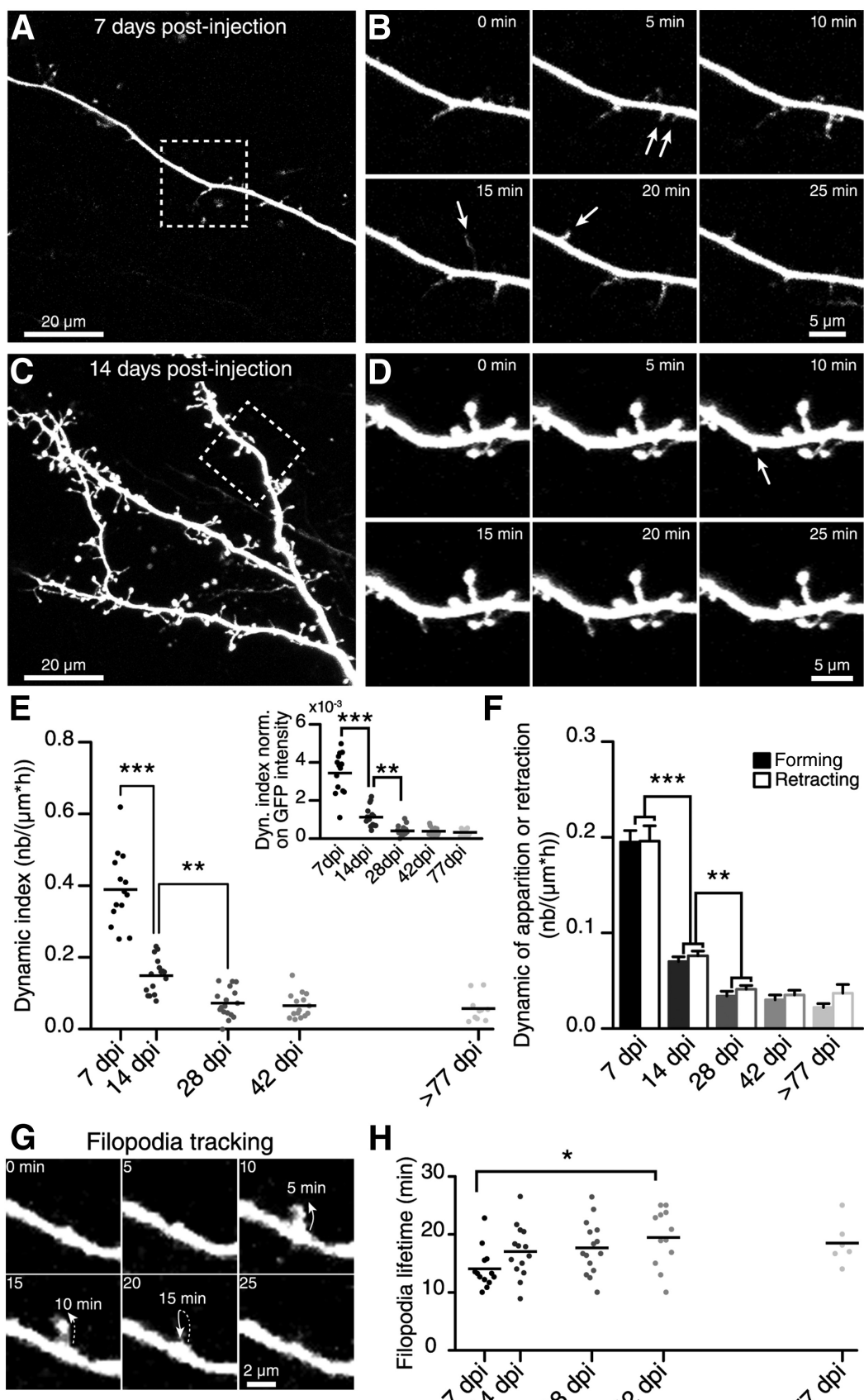

$\mathbf{F}$

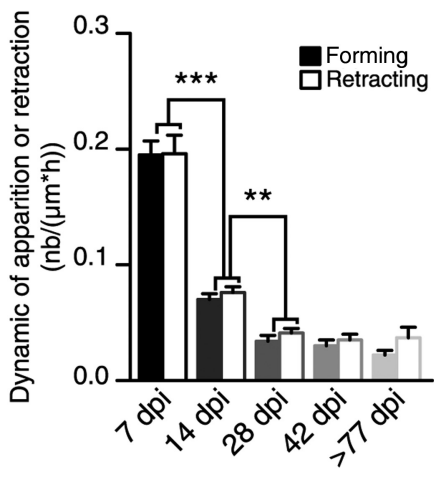

H

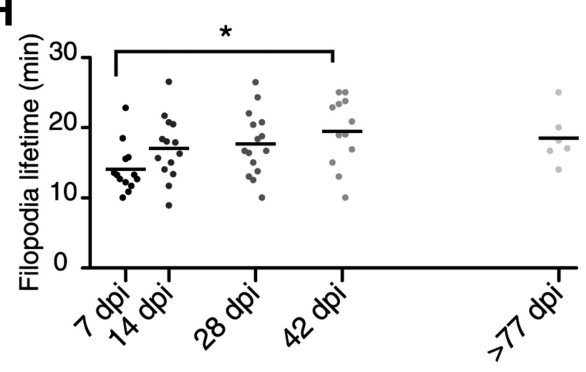

Figure 2. Time-lapse two-photon imaging reveals the rapid formation and retraction of filopodia on the dendrites of adultborn GCs. A, Two-photon maximum projection images of distal dendrite arborization in the EPL of an adult-born GC at 7 DPI. $\boldsymbol{B}$, Two-photon time-lapse images of the boxed region in $\boldsymbol{A}$. The arrows indicate filopodia forming on the dendrite. $\boldsymbol{C}$, Two-photon maximum projection images of distal dendrite arborization in the EPL of an adult-born GC at 14 DPI. $\boldsymbol{D}$, Two-photon time-lapse images of the boxed region in $\boldsymbol{C}$. Note the lower number of forming filopodia (arrows) on the dendrites of the GCs at this later maturational stage. $\boldsymbol{E}$, Quantification of the filopodia dynamic expressed as the dynamic index (see Material and Methods) on adult-born cell dendrites at different maturational stages. The dynamic index decreases as cells mature and form mature spines. Inset, Values of the dynamic index normalized on the average fluorescence intensity of each cell for different maturational stages of adult-born GCS. $\boldsymbol{F}$, Quantification of the number of forming or retracting filopodia normalized on the dendritic length and acquisition duration for the different maturational stages; $n=14,16,17,15$, and 10 cells at 7, 14, 28, 42, and $\geq 77 \mathrm{DPI}$ respectively. $\boldsymbol{G}$, Example of filopodia lifetime tracking. $\boldsymbol{H}$, Filopodia lifetime measurements at different maturational stages of adult-born $\mathrm{GCs} ; n=13,14,16,14$, and 9 cells for 7, 14, 28, 42, and $\geq 77 \mathrm{DPI}$, respectively. ${ }^{*} p<0.05 ;{ }^{* *} p<0.01$; ${ }^{* * *} p<0.001$ using a one-way ANOVA with Tukey's post hoc test. unclear. Because adult-born GCs do not receive direct synaptic inputs from sensory neurons (Shepherd et al., 2004) and spontaneously released glutamate modulate the filopodia dynamic of new interneurons at early maturational stages (Fig. 3), it is con- 
A
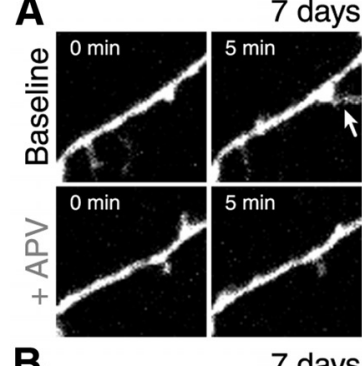

B
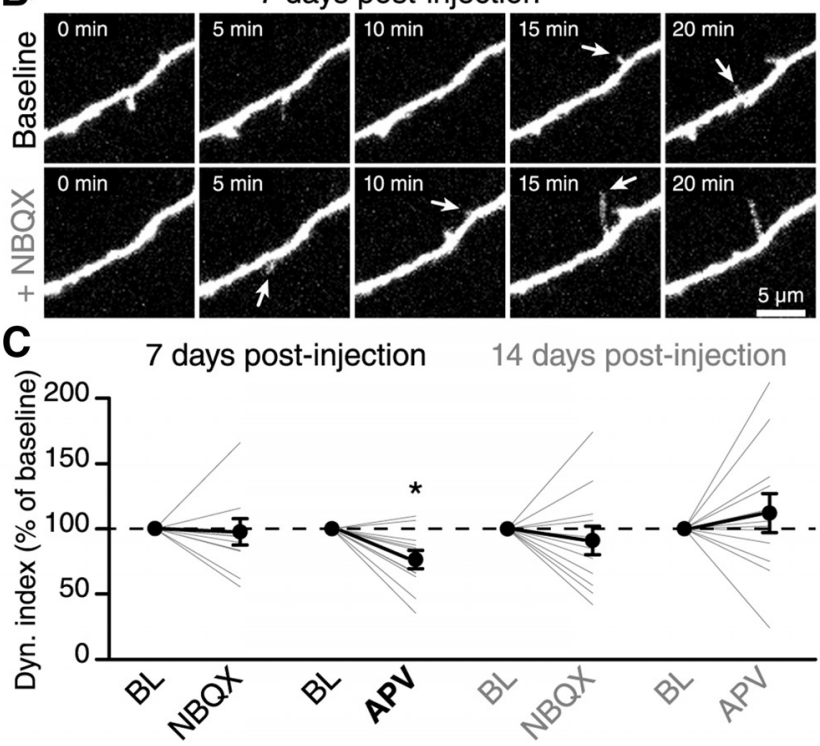

Figure 3. NMDAR activity is required for the BL filopodia dynamic at early maturational stages. $\boldsymbol{A}, \boldsymbol{B}$, Time-lapse two-photon imaging illustrating the effect of the application of APV, an NMDARs antagonist $(\boldsymbol{A})$ or NBQX, an AMPARs antagonist $(\boldsymbol{B})$ on the spontaneous filopodia dynamic of immature adult-born GCS at 7 DPI. C, Summary of the dynamic index following the application of NBQX or APV on adult-born GCs at 7 and 14 DPI. Only the application of APV at 7 DPI reduced the spontaneous filopodia dynamic; $n=11$ for NBQX and $n=10$ for APV application at $7 \mathrm{DPI}$ and $n=12$ for both NBQX and APV application at $14 \mathrm{DPI}$. $p<0.05$ using a paired Student's $t$ test.

ceivable that odor stimulation induces the activation of mitral cells, which in turn control the synaptogenesis of adult-born GCs.

To test this hypothesis, we monitored the filopodia dynamic on the dendrites of adult-born GCs following the stimulation of principal cells. The stimulating electrode was placed in the LOT where the axons of mitral cells converge, and the pattern of activity mimicking mitral cell responses to odors was applied (Cang and Isaacson, 2003). To ascertain that the imaged cell was in the region activated by the electrical stimulation, we also performed local field-potential recordings from that area (Fig. $4 A$ ). We recorded the BL dynamic for $45 \mathrm{~min}$ (one $z$-stack acquisition every $5 \mathrm{~min}$ ) followed by another $45 \mathrm{~min}$ imaging segment in which every image acquisition was synchronized with the LOT stimulation (Fig. 4B). Our results showed that stimulating principal cells induces an increase in the filopodia dynamic on the distal dendrites of adult-born GCs at 7 DPI compared with the BL level $(0.30 \pm 0.05$ at $\mathrm{BL}$ and $0.36 \pm 0.06$ following LOT stimulation, $n=13$ cells; Fig. $4 C$ ). The dynamic on the dendrites increased by an average of $24.1 \pm 9.5 \%(n=13$ cells; Fig. $4 C, E)$. Because we used longer imaging sessions (90 $\mathrm{min}$ ) in these experiments, we also performed control experiments imaging adult-born GCs for the same period of time, but without mitral cell stimulation. These experiments showed that the level of filopodia dynamic is very stable during the 90 min imaging period (Fig. $4 E$; BL-BL condition at $7 \mathrm{DPI}$ ) and that the increase in the filopodia dynamic observed following LOT stimulation (Fig. 4E; BL-stimulation condition at $7 \mathrm{DPI}$ ) is not due to a longer imaging time. Interestingly, the same pattern of mitral cell stimulation had no effect on the filopodia dynamic on the distal dendrites of more mature 14 DPI adult-born GCs (Fig. 4D). Compared with the BL filopodia dynamic on the distal dendrites of adult-born GCs at 14 DPI, the LOT stimulation did not induce any significant changes in the dynamic index $(0.16 \pm 0.02$ at $\mathrm{BL}$ and $0.15 \pm 0.03$ following LOT stimulation, $n=11$ cells; Fig. $4 D, E)$.

The dynamic index provided a direct measurement of the number of forming/retracting structures on the dendrites of adult-born GCs but did not indicate whether the filopodia stabilize after the increased mitral cell activity. We thus measured the lifetime of the filopodia (Fig. $4 F$ ). The lifetime of the filopodia that form on the dendrites of adult-born GCs at 7 and 14 DPI was similar to the BL value following the stimulation of the LOT (Fig. $4 F$ ). It should be noted, however, that in these experiments the filopodia were tracked for only $45 \mathrm{~min}$, which might be insufficient to detect significant changes in their lifetime.

Because in these experiments we used the stimulation protocol mimicking the responses of principal cells to odors (pattern stimulation), we next asked how specific this pattern stimulation is in inducing the filopodia dynamic. To address this question we used the stimulation protocol consisting from the same number of electrical pulses as during pattern stimulation, but given in the random order during the $30 \mathrm{~s}$ stimulation period (Fig. $4 G$ ). This stimulation protocol, hereinafter called random stimulation, did not induce any changes in the dynamic index $(108 \pm 15 \%$ from the BL dynamic, $n=9$ cells; Fig. $4 H$ ) and lifetime of filopodia (Fig. 4I) at 7 DPI. Overall, these results indicated that there is a critical time period when the specific pattern of activity of principal cells influences the maturation and integration of adultborn GCs by affecting the dynamic but not the lifetime of filopodia on the distal dendrites.

The increased filopodia dynamic of adult-born GCs at 7 DPI following the LOT stimulation depends on the activation of NMDARs

The molecular cues controlling the maturation and integration of adult-born GCs in the adult OB remain largely unknown. Because our results showed that LOT stimulation with a pattern of activity mimicking the responses of mitral cells to odor stimulation modulates the filopodia dynamic of adult-born GCs and that BL filopodia dynamic is influenced by spontaneously released glutamate (Fig. 3), we decided to evaluate the role of glutamate in the LOT stimulation-induced increase in the filopodia dynamic.

We hypothesized that the increased filopodia dynamic on GC dendrites at 7 DPI but not 14 DPI following the stimulation of principal cells is mediated by the activation of the NMDARs but not AMPARs. To test this hypothesis, we performed two-photon imaging of adult-born GCs at 7 DPI and 14 DPI under three conditions: (1) we first recorded the filopodia dynamic of an adult-born GC under BL conditions for $45 \mathrm{~min}$, (2) we then stimulated the mitral cells and imaged the morphological changes of the adult-born GC for another $45 \mathrm{~min}$, and (3) we performed for additional $45 \mathrm{~min}$ two-photon imaging of this GC in the presence of NMDAR (APV, $50 \mu \mathrm{M})$ and AMPAR (NBQX, $25 \mu \mathrm{M})$ antagonists and mitral cells stimulation. At an early maturational stage (7 DPI), the bath application of APV completely blocked the increase in the filopodia dynamic on the distal dendrites observed following the stimulation of the LOT (BL-stimu- 
A

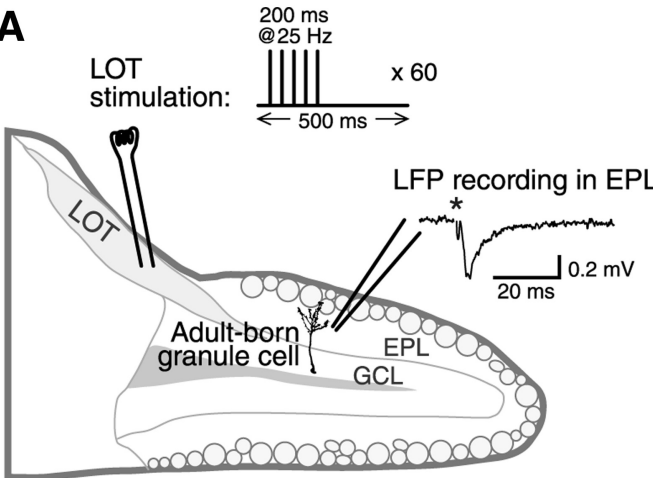

C

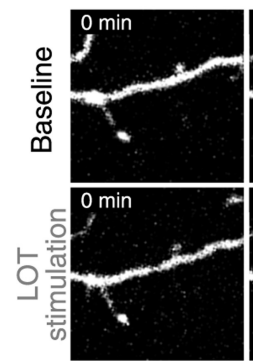

D

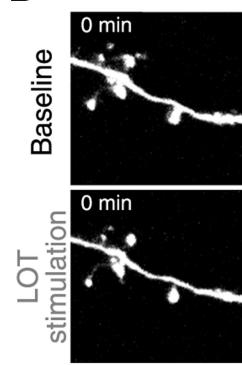

E

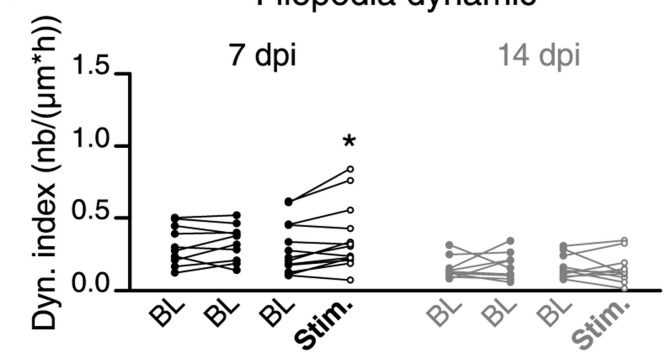

B

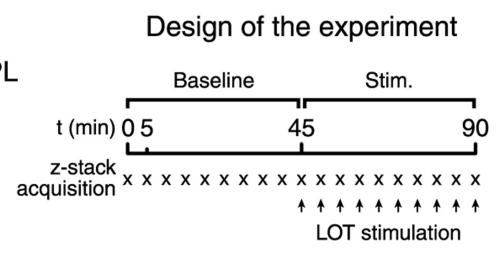

90

7 days post-injection

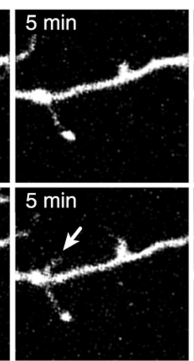

14 days post-injection
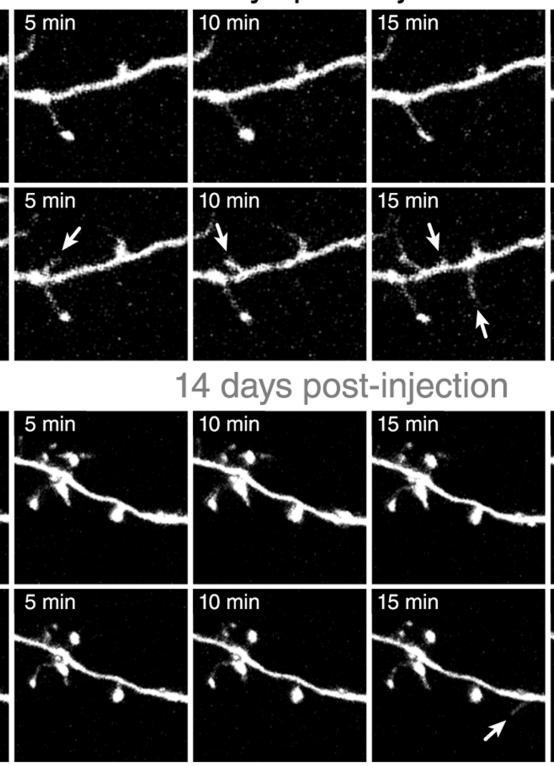

$\mathbf{F}$

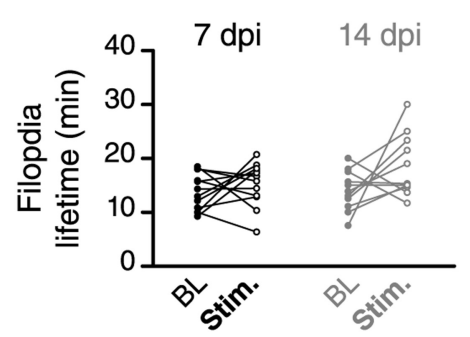

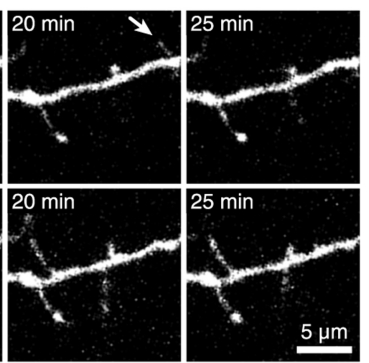

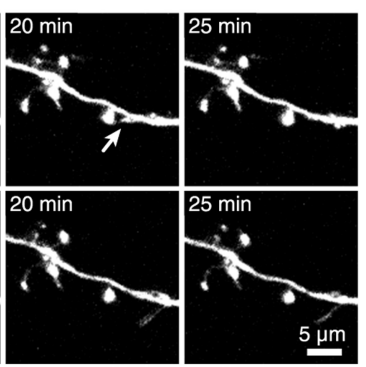

Filopodia lifetime
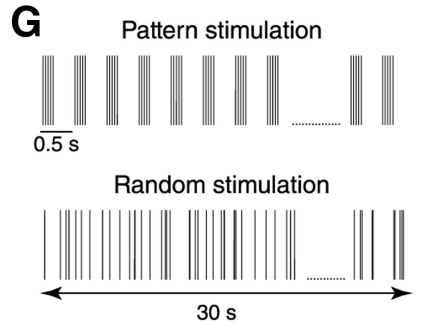

$\mathrm{H}$

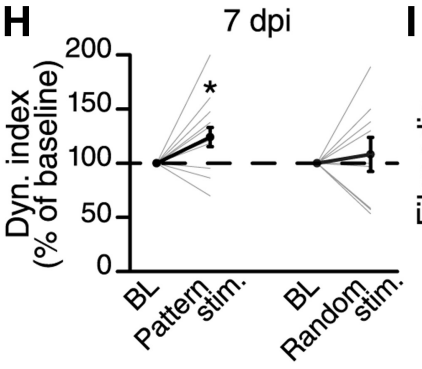

(a)

the BL filopodia dynamic on the distal dendrites of adult-born GCs at 7 DPI (Fig. 3). The application of NBQX had no effect on the increase in the filopodia dynamic observed following the stimulation of the mitral cells (BL-stimulation: $140 \pm 15 \%$ and BL-stimulation + NBQX: $145 \pm$ $20 \% ; n=10$ cells; Fig. $5 B$ ). Neither antagonist had an effect on the lifetime of the filopodia (Fig. 5C). Similarly, because the stimulation of mitral cells did not induce any changes in the filopodia dynamic on the distal dendrites of adult-born GCs at 14 DPI (Fig. 4) and the application of APV and NBQX did not affect the BL filopodia dynamic at this maturational stage (Fig. 3), the application of NMDARs and AMPARs antagonists also did not change the dynamic index or lifetime of the filopodia at 14 DPI following LOT stimulation (Fig. 5D-F). Overall, these results indicated that the increase in the filopodia dynamic observed on the distal dendrites of adult-born GC at 7 DPI, but not at 14 DPI, is mediated by NMDAR activity.

We next examined whether usedependent NMDARs blocker MK-801 (25 $\mu \mathrm{M})$ would be effective in blocking LOT stimulation-induced increase in filopodia dynamic on the distal dendrites of adultborn GCs at 7 DPI. We thus performed imaging of filopodia dynamic under BL condition for $45 \mathrm{~min}$ followed by LOT stimulation and imaging for additional 45 min of adult-born GC dendrite. We then applied MK-801 for $10 \mathrm{~min}$ and resumed LOT stimulation and imaging of the

\section{$\leftarrow$}

Time-lapse imaging of the distal dendrite of a $7 \mathrm{DPI}$ and a 14 DPI adult-born GC before and after the stimulation. The arrows indicate the formation of filopodia. $\boldsymbol{E}$, Summary graph showing the dynamic index for all recordings performed at 7 and 14 DPI. $n=10$ cells for BL-BL and $n=13$ for BL-stimulation at $7 \mathrm{DPI} ; n=9$ cells for BL-BL and $n=11$ for BL-stimulation at $14 \mathrm{DPI} . \boldsymbol{F}$, The stimulation of the mitral cells had no influence on the lifetime of the filopodia at 7 and $14 \mathrm{DPI} ; n=11$ cells for $7 \mathrm{DPI}$ and $14 \mathrm{DPI}$. G, Comparison between the "pattern" and "random" stimulation protocols. The pattern stimulation protocol is the same as illustrated in $\boldsymbol{A}$. Both stimulation protocols use the same number of single LOT stimulations during 30 s. $\boldsymbol{H}$, The effect of pattern and random stimulations of mitral cells on the dynamic index of adult-born GCs at 7 DPI. The dynamic index is plotted as the percentage of the BL value. I, Quantification of filopodia lifetime; $n=13$ and 9 cells for pattern and random stimulation protocols, respectively. ${ }^{*} p<0.05$ and ${ }^{* *} p<0.01$ using a paired Student's $t$ test.

Figure 4. Mitral cell firing activity controls the integration of the adult-born GCs. A, A schematic drawing showing the methodology used to stimulate mitral cells in horizontal acute slices of the OB. We stimulated the mitral cell axons in the LOT using a stimulation pattern that mimicked the responses of these principal cells to odor stimuli (see inset; sixty $200 \mathrm{~ms}$ pulses at $25 \mathrm{~Hz}$ at 0.5 s intervals). The extracellular local field potential (LFP) was recorded close to the distal dendrites of adult-born GCs to ensure that the stimulation was effective. We then performed time-lapse two-photon imaging on the distal dendrites of an adult-born GC in a region with an LFP response following the LOT stimulation. $\boldsymbol{B}$, We first recorded a $45 \mathrm{~min} B \mathrm{~L}$ period without stimulation. We then applied the stimulation pattern described in $\boldsymbol{A}$ at 5 min intervals (synchronized with the time-lapse acquisition). $\boldsymbol{C}, \boldsymbol{D}$ 
A

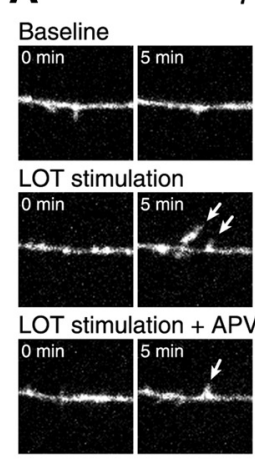

B

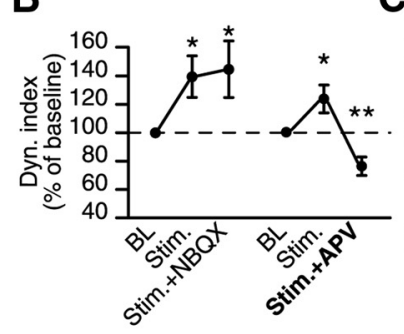

G
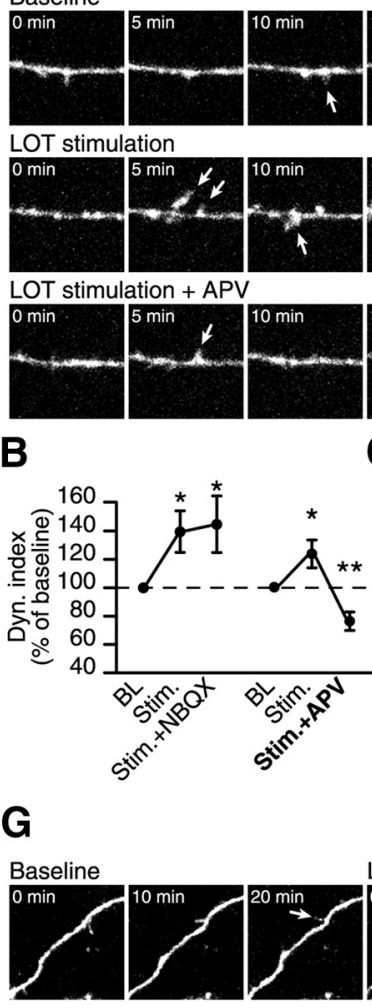

7 days post-injection
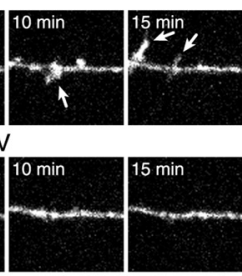

C

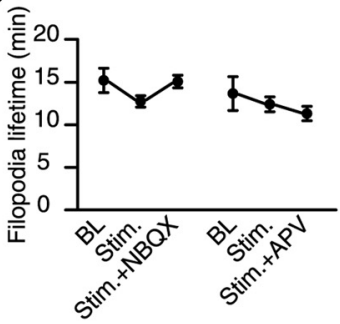

7 days post-injection

LOT stimulation
LOT

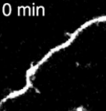

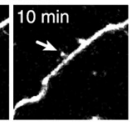

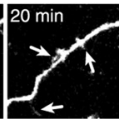

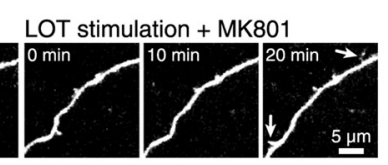

D

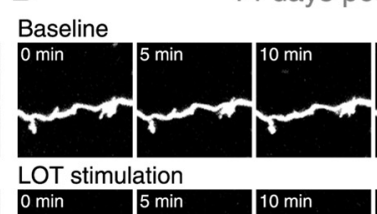

14 days post-injection
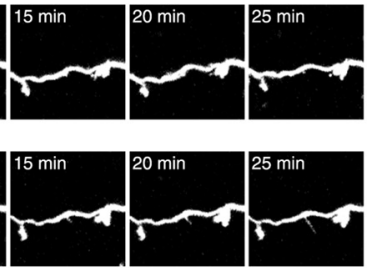

LOT stimulation + APV

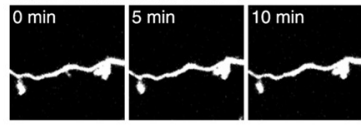

E

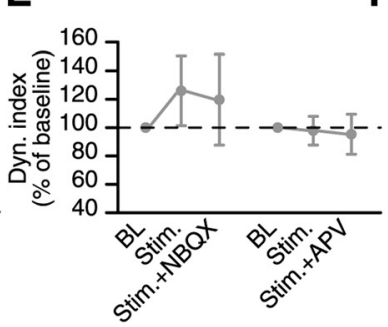

F
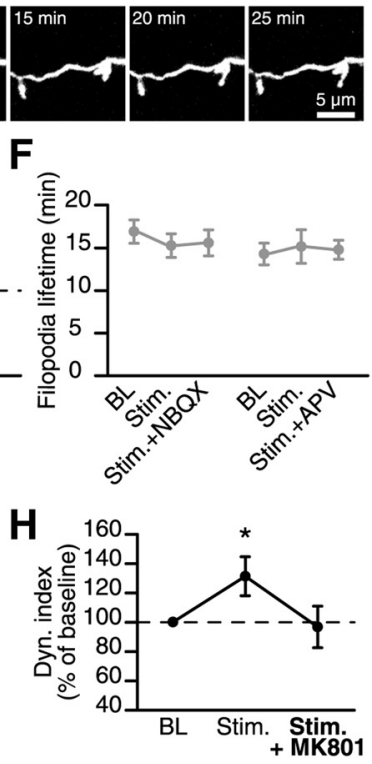

Figure 5. The mitral cell activity-induced filopodia dynamic on the dendrites of immature adult-born GCs is dependent on the activation of NMDARs. A, Time-lapse two-photon imaging of an adult-born GC at 7 DPI under BL conditions (top), following the stimulation of mitral cells (middle), and following the stimulation of mitral cells in the presence of APV (bottom). The arrows indicate forming filopodia. $B$, The role of NMDARs and AMPARs in the increase in the filopodia dynamic on the distal dendrites of adult-born GCs at 7 DPl induced by mitral cell stimulation. The dynamic index is plotted as a percentage of the BL value. C, Quantification of filopodia lifetime; $n=10$ for NBQX and $n=12$ for APV. D, Time-lapse two-photon imaging of an adult-born GC at 14 DPI under BL conditions (top), following the stimulation of mitral cells (middle), and following the stimulation of mitral cells in the presence of APV (bottom). The arrows indicate forming filopodia. $E$, The role of NMDARs and AMPARs in the filopodia dynamic on the distal dendrites of adult-born GCS at 14 DPI following the stimulation of mitral cells. The dynamic index is plotted as a percentage of the BL value. $\boldsymbol{F}$, Quantification of the filopodia lifetime; $n=12$ cells for both NBQX and APV. G, Time-lapse two-photon imaging of an adult-born GC at 7 DPI under BL conditions (left), following the stimulation of mitral cells (center), and following the stimulation of mitral cells in the presence of MK-801, a use-dependent NMDAR antagonist (right). $\boldsymbol{H}$, The effect of NMDAR activation on the increase in filopodia dynamic on distal dendrites of adult-born GCs at 7 DPI induced by mitral cell stimulation. The dynamic index is plotted as a percentage of the BL value; $n=9$ cells. ${ }^{*} p<0.05$ and ${ }^{* *} p<0.01$ using a paired Student's $t$ test to compare experimental and BL values.

adult-born GC for another 45 min. Application of MK-801 completely blocked the LOT stimulation-induced effect $(96.6 \pm$ $14.2 \%$ as compared with the BL; $n=9$ cells; Fig. $5 G, H)$. Although the decrease below the BL level induced by APV was pronounced compared with MK-801 (Fig: 5, compare $B, H$ ), there was no statistically significant differences between these data $(p=0.09)$.

The application of NMDA is sufficient to induce the formation of new filopodia on the distal dendrites of immature adult-born GCs

These results indicated that NMDAR activation in immature adult-born GCs at 7 DPI is required to induce a filopodia dynamic on their distal dendrites. Our next step was to determine whether the local application of NMDA is sufficient to induce the formation of new filopodia. To this end, we recorded the BL dynamic for a period of $45 \mathrm{~min}$. We then positioned a pipette containing NMDA (100 mM) and AlexaFluor $594(10 \mu \mathrm{M}$; to visualize the pipette position) $\sim 5 \mu \mathrm{m}$ from the distal dendrites of adult-born GCs and applied a brief pulse of negative current ranging from 150 to $250 \mathrm{nA}$ to the pipette to release NMDA near the distal dendrites of adult-born GCs (7 and 14 DPI). In control experiments, we used a pipette containing only ACSF and showed that the application of the current alone has no effect on the filopodia dynamic (data not shown). The local application of NMDA by iontophoresis to the dendrites of immature adultborn GCs (7 DPI) induced the formation of filopodia (Fig. 6A). There was a $225 \pm 71 \%(n=10$ cells $)$ increase in the dynamic index of the dendrites located near the pipette (Fig. $6 B$ ). No changes in the filopodia dynamic were observed at positions further away from the iontophoresis location (Fig. 6B). At a later maturational stage (14 DPI), as expected, NMDA iontophoresis had no effect on the filopodia dynamic on the distal dendrites of adult-born GCs $(-7.3 \pm 34.1 \%$ of changes, $n=8$ cells; Fig. $6 C, D)$. These results showed that NMDAR activity is important in inducing the filopodia dynamic at the early but not late stages of adult-born GC maturation.

Decreasing the extracellular $\mathrm{Mg}^{2+}$ concentration led to filopodia formation on the distal dendrites of mature adultborn GCs following NMDA iontophoresis

Our results revealed that adult-born GCs have different responses in their early and late maturational stages to the stimulation of mitral cells, NMDA iontophoresis, and the bath application of an NMDAR antagonist. Although these results suggested that there 

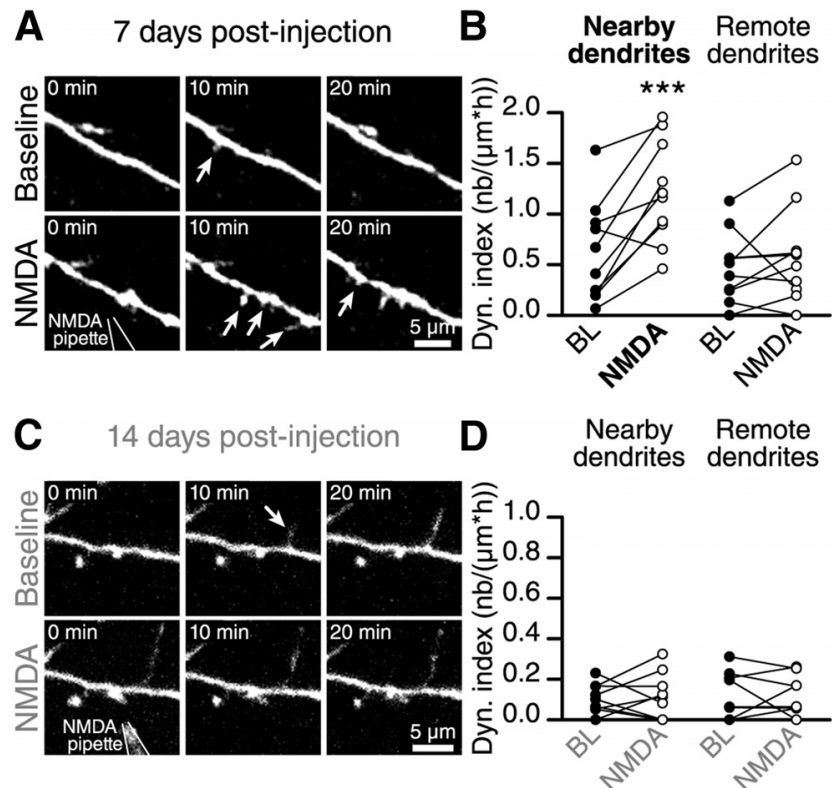

Figure 6. NMDAR activity enhances the filopodia dynamic at early maturational stages. $\boldsymbol{A}$, Time-lapse imaging showing the increase in the filopodia dynamic on the distal dendrites of adult-born GC at 7 DPI after the NMDA iontophoresis. B, Quantification of the dynamic index of nearby and remote dendritic segments (based on the location of the iontophoresis pipette) of adult-born GCs at 7 DPI ( $n=10$ cells). C, Time-lapse imaging showing that the application of NMDA to the distal dendrites of mature adult-born GCs at 14 DPI does not alter the filopodia dynamic. $D$, Quantification of the dynamic index following the NMDA iontophoresis onto nearby and distant dendritic segments of mature adult-born GCs at $14 \mathrm{DPI}\left(n=9\right.$ cells). ${ }^{* * *} p<0.001$ using a paired Student's $t$ test.

is a critical period in the development of adult-born GCs, the mechanisms involved in the different responses of immature and mature adult-born GCs remain unclear. Interestingly, however, it has been shown that the maturation of adult-born GCs is accompanied by progressive membrane hyperpolarization (Carleton et al., 2003). It is well established that, at the resting membrane potential of mature neurons, NMDARs are blocked and that their activation requires the extrusion of $\mathrm{Mg}^{2+}$ ions from NMDA channel pore by membrane depolarization (Sanz-Clemente et al., 2013). Because immature adult-born GCs have a more depolarized membrane potential than mature interneurons (Carleton et al., 2003), it is conceivable that an $\mathrm{Mg}^{2+}$ block of NMDARs is less efficient at early maturational stages. This in turn may explain the distinct responses to mitral cell stimulation and NMDA iontophoresis of adult-born GCs at their different maturational stages. We thus decided to test whether relieving the $\mathrm{Mg}^{2+}$ block of NMDARs in mature adult-born GCs would allow filopodia dynamic in response to NMDA iontophoresis.

We first recorded the intrinsic membrane properties of adultborn GCs at their different maturational stages. We observed that immature adult-born GCs (7 DPI) have a less hyperpolarized membrane potential $(-41.2 \pm 1.8 \mathrm{mV}, n=29$ cells, vs $-65.8 \pm$ $1.9 \mathrm{mV}, n=19$ cells; Fig. $7 A$ ), a higher membrane resistance $(2.2 \pm 0.2 \mathrm{G} \Omega, n=25$ cells, vs $0.86 \pm 0.07 \mathrm{G} \Omega, n=21$ cells, respectively; Fig. $7 A)$, and a lower membrane capacitance $(8.7 \pm$ $0.5 \mathrm{pF}, n=29$ cells, vs $17.8 \pm 1.0 \mathrm{pF}, n=24$ cells; Fig. $7 A$ ) than mature adult-born GCs (14 DPI), which is in agreement with previous studies (Carleton et al., 2003; Nissant et al., 2009). The maturation of adult-born GCs is thus accompanied by a $25 \mathrm{mV}$ hyperpolarization of the resting membrane potential, which may
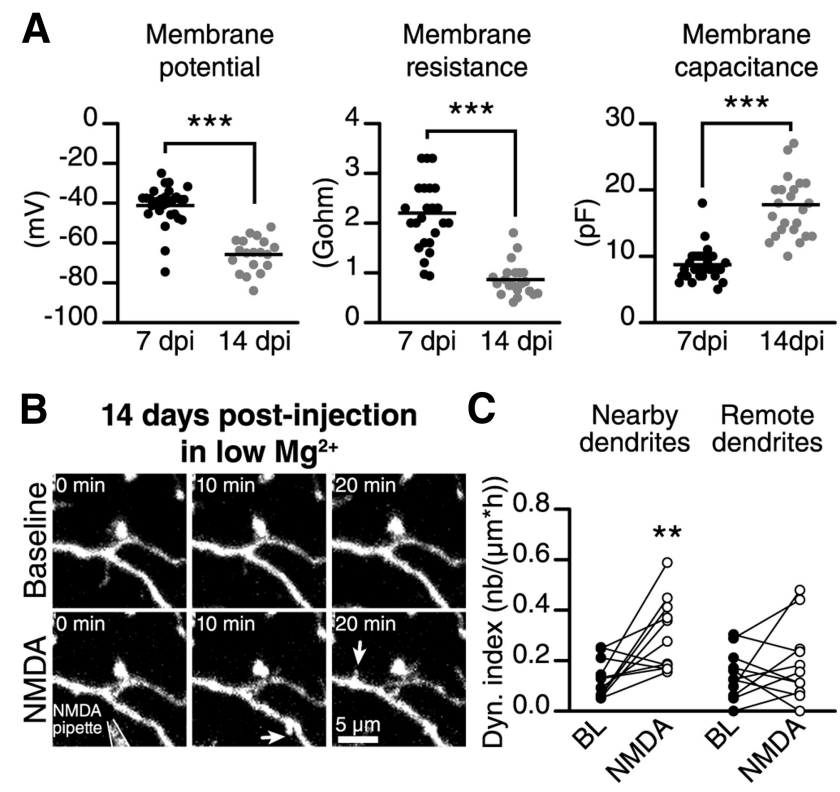

Figure 7. Decreasing the extracellular $\mathrm{Mg}^{2+}$ concentration makes filopodia on the dendrites of mature adult-born GCs sensitive to NMDA iontophoresis. $A$, Adult-born GCs membrane properties recorded in the whole-cell patch-clamp configuration; $n=29$ and 19 cells for membrane potential, $n=25$ and 24 cells for membrane resistance and $n=29$ and 21 cells for membrane capacitance at 7 and 14 DPI, respectively. ${ }^{* * *} p<0.001$ using a Student's $t$ test. $\boldsymbol{B}$ Time-lapse two-photon imaging showing the increase in the filopodia dynamic on the dendrites of a 14 DPI adult-born GC following the application of NMDA and the reduction of the extracellular $\mathrm{Mg}^{2+}$ concentration. C, Quantification of the dynamic index on the nearby and remote dendritic segments of mature adult-born GCs at 14 DPI following the application of NMDA and the reduction in the extracellular $\mathrm{Mg}^{2+}$ concentration $\left(n=12\right.$ cells). ${ }^{* *} p<0.01$ using a paired Student's $t$ test.

have an impact on the level of activation of NMDARs at this maturational stage.

To directly determine whether the absence of a response of mature adult-born GCs to NMDA iontophoresis was due to a more pronounced $\mathrm{Mg}^{2+}$ block of NMDARs, we decreased the extracellular $\mathrm{Mg}^{2+}$ concentration for $45 \mathrm{~min}$ and locally applied NMDA to the distal dendrites of mature adult-born GCs. Interestingly, decreasing the extracellular $\mathrm{Mg}^{2+}$ concentration made mature adult-born GCs responsive to NMDA iontophoresis (Fig. $7 B)$. NMDA iontophoresis on the distal dendrites of mature adult-born GCs (14 DPI) induced the formation of new filopodia and increased the dynamic index by $231 \pm 102 \%(n=12$ cells; Fig. 7C). We observed no change in the filopodia dynamic on dendrites located far away from the iontophoresis pipette (Fig. $7 C)$. These results suggested that the distinct responses of immature and mature adult-born GCs are at least partially due to the efficiency of the $\mathrm{Mg}^{2+}$ block of NMDARs at different maturational stages.

\section{Discussion}

The present study revealed the structural dynamic that occurs at the early stages of adult-born GC maturation and integration. We showed that the filopodia dynamic increased in immature adultborn GCs and decreased with cell maturation. This dynamic was induced by principal cells activity and was dependent on the activation of NMDARs on the distal dendrites of immature adultborn GCs. Interestingly, the maturation of bulbar interneurons was accompanied by a hyperpolarization of the resting membrane potential and an increase in the $\mathrm{Mg}^{2+}$ block of NMDARs on the distal dendrites of adult-born GCs. This in turn made 
filopodia on the dendrites of mature adult-born GCs insensitive to mitral cell stimulation and NMDA iontophoresis. Our results showed that immature and mature adult-born GCs have a distinct structural dynamic in response to principal cell activity, suggesting that there is a critical period in the maturation and integration of bulbar interneurons.

\section{Structural dynamic and maturation of adult-born GCs}

Our morphological analysis of adult-born GCs at their different maturational stages revealed that immature interneurons sequentially acquire thin filopodia-like protrusions on their distal dendrites, which is followed by the formation of mushroom and stubby spines. Although it has been shown that new spines can be formed without a filopodial stage (Kwon and Sabatini, 2011), it is generally thought that filopodia are precursors of mature mushroom and stubby spines and serve as initial contact sites between presynaptic and postsynaptic neurons (Fiala et al., 1998; Jontes and Smith, 2000; Goda and Davis, 2003). The number of filopodia on the dendrites of pyramidal neurons decreases with cell maturation in the developing cortex and hippocampus (Fiala et al., 1998; Jontes and Smith, 2000), which provides support for this hypothesis. In the $\mathrm{OB}$, however, the density of thin filopodia remained stable throughout the maturation of adult-born GCs and their density at $163 \mathrm{DPI}$, the longest postinjection time investigated in our study, was similar to that observed at 7 DPI. Interestingly, although the density of these thin filopodia on the distal dendrites of adult-born GCs remained stable, their dynamic decreased markedly. The dynamic index dropped almost sixfold between 7 DPI and $28 \mathrm{DPI}$, indicating that many of the filopodia-like protrusions on the distal dendrites of mature adult-born GCs are quite stable and/or display a structural dynamic beyond the timeframes used in our study (i.e., longer than $2 \mathrm{~h}$ ). Although our study did not allow us to determine which of these two possibilities was the most plausible, it did suggest that the distal dendrites of mature adult-born GCs possess at least two different types of filopodia-like structures, a relatively stable filopodia that showed no noticeable dynamic during the $2 \mathrm{~h}$ of imaging, and filopodia that displayed a rapid dynamic and the same lifetime as the ones on immature GC dendrites. It is thus tempting to speculate that the role of some thin filopodia-like protrusions on the distal dendrites of mature adult-born GCs may go beyond their function in synaptogenesis. Some of them may be stabilized and act as functional synapses.

The filopodia dynamic on the dendrites of immature but not mature adult-born GCs was sensitive to LOT stimulation. A pattern of activity that mimics the responses of mitral cells to odor presentation increased the dynamic index or the number of filopodia on the dendrites of immature GCs. It would have been also expected that principal cells stimulation would lead to the increased number of initial contacts between immature GCs and principal neurons. Surprisingly, however, the lifetime of filopodia was similar to that observed under BL conditions. It is thus peculiar that the activity of principal cells induced the formation of new filopodia, but that these contacts remained transient and retracted within 10-20 min. These data are consistent with previous observations showing that experience-dependent modifications in the motility of dendritic filopodia are not associated with changes in the spine density (Lendvai et al., 2000). It is conceivable, however, that the increased number of initial contacts may be followed by the formation of new mature spines, which could not be detected in our study because of the short acquisition periods (45 min). It has been suggested that the retraction of filopodia could be followed by the generation of shaft/ spine synapses (Dailey and Smith, 1996; Ziv and Smith, 1996). Our results, showing that the filopodia dynamic was high when the number of shaft/spine spines was low and decreased as the number of spines increased, are consistent with this suggestion. Alternatively, the stimulation of principal cells may induce not only the formation of new filopodia but also stabilize pre-existing filopodia, which were not taken into consideration in our lifetime measurements. The presence of stable filopodia on mature adultborn GCs is consistent with this possibility.

It should be also noted that in addition of activating the bulbar principal neurons, the LOT stimulation may also activate centrifugal fibers from the olfactory cortex that in turn may induce the structural modification of adult-born GCs. Although we cannot formally rule out this possibility and further experiments with selective optogenetic stimulation of mitral cells or centrifugal axons are required; it has been shown that centrifugal axons from the olfactory cortex form synapses on the proximal dendrites of GCs (Sassoè-Pognetto et al., 2003; Balu et al., 2007). In our experiments, however, we analyzed the filopodia dynamic on the distal dendrites of adult-born GCs. Although it remains possible that simultaneous activation of both the mitral cells and the centrifugal fibers may be required to induce changes in the filopodia dynamic, our experiments with NMDA iontophoresis revealed that the activation of NMDARs on the distal dendrites of immature adult-born GCs is sufficient in inducing filopodia dynamic.

\section{NMDARs play a role in the structural dynamic of adult- born GCs}

The filopodia dynamic on the dendrites of immature adult-born GCs was dependent on NMDAR but not AMPAR activation. The application of NMDAR antagonists completely blocked the mitral cell stimulation-induced filopodia dynamic on the distal dendrites of immature GCs. APV application also markedly reduced the BL filopodia dynamic, suggesting that spontaneous glutamate release from principal cells induces the formation of new filopodia on the distal dendrites of immature adult-born GCs. Last, NMDA iontophoresis was sufficient to trigger the formation of new filopodia on the dendrites of immature GCs. All these data unequivocally demonstrate that NMDARs are required for the structural dynamic of adult-born GCs at their early maturational stages. Interestingly, we also observed that application of APV induced higher, albeit not significant, decrease in the LOTinduced filopodia dynamic as compared with use-dependent NMDARs antagonist MK-801. Although MK-801 could be used for distinguishing the relative contribution of synaptic versus extrasynaptic NMDARs (Tovar and Westbrook, 1999; Harney et al., 2008), it should be noted that in the developing synapses the overall level of glutamate release may be substantially higher compared with mature synapses (Bolshakov and Siegelbaum, 1995). In addition, the stimulation pattern used in our study, that mimics activity of principal cells to odors, would likely induce a substantial amount of glutamate release. Thus, it is possible that LOT stimulation may not only induce activation of synaptic NMDARs, but also perisynaptic and even extrasynaptic NMDARs and MK-801 could effectively block all these receptors in the immature adult-born GCs.

Overall our results are consistent with the role played by NMDARs in synaptic development in other regions of the brain (Liao et al., 1999; Jontes and Smith, 2000; Hensch, 2004; Kwon and Sabatini, 2011). In the OB, the deletion of the NR1 subunit of NMDARs from adult-born neuronal precursors induces their death (Lin et al., 2010; Platel et al., 2010). Interestingly, many of these cells die during the peak of synaptic development (Lin et al., 
2010), which is consistent with our findings showing that NMDARs play an important role in the initial stages of adultborn GCs maturation and integration. It has been suggested that the successful integration of adult-born GCs underlies their maintenance and survival in the bulbar network (Lledo and Saghatelyan, 2005; Yamaguchi and Mori, 2005).

Our results were also consistent with the recent demonstration that NMDARs play a facilitating role in synapse formation and the maturation of adult-born GCs (Kelsch et al., 2012). Interestingly, however, the deletion of the NR2B subunit, which is usually expressed at early maturational stages (Monyer et al., 1994), only affects the glutamatergic input on the proximal dendrites of adult-born GCs (Kelsch et al., 2012). No significant differences in the number of PSD-95-GFP puncta on the distal dendrites of NR2B-deficient GCs were observed (Kelsch et al., 2012), whereas our study suggested that NMDARs play an important role in the formation and dynamic of filopodia on the dendrites of immature adult-born interneurons. Several explanations could account for these differences. First, Kelsch et al. (2012) only studied adult-born GCs that did not die during migration (Platel et al., 2010). Second, glutamatergic synapses on the proximal and distal dendrites of adult-born GCs may contain NMDARs with different subunit compositions since the number, localization, and subunit composition of NMDARs are regulated in a synapse-specific manner (Sanz-Clemente et al., 2013). Third, Kelsch et al. (2012) counted the number of mature PSD-95 containing spines, whereas we evaluated the dynamic of filopodia-like protrusions. In fact, our results showed that NMDARs play an important role in the formation and dynamic of filopodia, but not their stabilization. This may suggest that NMDARs on the distal dendrites of adult-born GCs are involved in the establishment of initial contacts between newly arrived interneurons and principal cells, whereas NMDARs on proximal dendrites play a role in the maturation and/or maintenance of synaptic connections.

\section{A critical period for the integration of adult-born GCs}

Our results showed that the stimulation of mitral cells, the application of NMDAR antagonists, and NMDA iontophoresis affect the filopodia dynamic on the distal dendrites of immature but not mature adult-born GCs. We also showed that GCs maturation is accompanied by the hyperpolarization of the resting membrane potential, which in turn leads to a more efficient $\mathrm{Mg}^{2+}$ block of NMDARs. These results all suggested that there is a critical period for the maturation and integration of adult-born GCs.

Our results are consistent with previous reports indicating that there is a critical period for the survival (Yamaguchi and Mori, 2005) and synaptic development (Kelsch et al., 2009) of adult-born GCs. Interestingly, however, the results we obtained by reducing the extracellular $\mathrm{Mg}^{2+}$ concentration also suggested that the critical period for the filopodia dynamic may be reopened when the release of glutamate from the principal cells coincides with the strong depolarization of mature adult-born GCs, which causes the extrusion of $\mathrm{Mg}^{2+}$ from the pore of the NMDA channel. It is tempting to speculate that different behavioral paradigms involving odor stimulation with a coincident top-down excitatory input to interneurons may reopen the critical period and trigger the filopodia dynamic on the distal dendrites of mature adult-born GCs.

\section{References}

Alvarez-Buylla A, Garcia-Verdugo JM (2002) Neurogenesis in adult subventricular zone. J Neurosci 22:629-634. Medline
Balu R, Pressler RT, Strowbridge BW (2007) Multiple modes of synaptic excitation of olfactory bulb granule cells. J Neurosci 27:5621-5632. CrossRef Medline

Bastien-Dionne PO, David LS, Parent A, Saghatelyan A (2010) Role of sensory activity on chemospecific populations of interneurons in the adult olfactory bulb. J Comp Neurol 518:1847-1861. CrossRef Medline

Belluzzi O, Benedusi M, Ackman J, LoTurco JJ (2003) Electrophysiological differentiation of new neurons in the olfactory bulb. J Neurosci 23:1041110418. Medline

Bolshakov VY, Siegelbaum SA (1995) Regulation of hippocampal transmitter release during development and long-term potentiation. Science 269: 1730-1734. CrossRef Medline

Breton-Provencher V, Saghatelyan A (2012) Newborn neurons in the adult olfactory bulb: unique properties for specific odor behavior. Behav Brain Res 227:480-489. CrossRef Medline

Cang J, Isaacson JS (2003) In vivo whole-cell recording of odor-evoked synaptic transmission in the rat olfactory bulb. J Neurosci 23:4108-4116. Medline

Carleton A, Petreanu LT, Lansford R, Alvarez-Buylla A, Lledo PM (2003) Becoming a new neuron in the adult olfactory bulb. Nat Neurosci 6:507518. Medline

Dailey ME, Smith SJ (1996) The dynamics of dendritic structure in developing hippocampal slices. J Neurosci 16:2983-2994. Medline

Fiala JC, Feinberg M, Popov V, Harris KM (1998) Synaptogenesis via dendritic filopodia in developing hippocampal area CA1. J Neurosci 18: 8900-8911. Medline

Goda Y, Davis GW (2003) Mechanisms of synapse assembly and disassembly. Neuron 40:243-264. CrossRef Medline

Harney SC, Jane DE, Anwyl R (2008) Extrasynaptic NR2D-containing NMDARs are recruited to the synapse during LTP of NMDAR-EPSCs. J Neurosci 28:11685-11694. CrossRef Medline

Hensch TK (2004) Critical period regulation. Annu Rev Neurosci 27:549_ 579. CrossRef Medline

Jontes JD, Smith SJ (2000) Filopodia, spines, and the generation of synaptic diversity. Neuron 27:11-14. CrossRef Medline

Kelsch W, Lin CW, Lois C (2008) Sequential development of synapses in dendritic domains during adult neurogenesis. Proc Natl Acad Sci U S A 105:16803-16808. CrossRef Medline

Kelsch W, Lin CW, Mosley CP, Lois C (2009) A critical period for activitydependent synaptic development during olfactory bulb adult neurogenesis. J Neurosci 29:11852-11858. CrossRef Medline

Kelsch W, Li Z, Eliava M, Goengrich C, Monyer H (2012) GluN2Bcontaining NMDA receptors promote wiring of adult-born neurons into olfactory bulb circuits. J Neurosci 32:12603-12611. CrossRef Medline

Kopel H, Schechtman E, Groysman M, Mizrahi A (2012) Enhanced synaptic integration of adult-born neurons in the olfactory bulb of lactating mothers. J Neurosci 32:7519-7527. CrossRef Medline

Kwon HB, Sabatini BL (2011) Glutamate induces de novo growth of functional spines in developing cortex. Nature 474:100-104. CrossRef Medline

Lendvai B, Stern EA, Chen B, Svoboda K (2000) Experience-dependent plasticity of dendritic spines in the developing rat barrel cortex in vivo. Nature 404:876-881. CrossRef Medline

Liao D, Zhang X, O’Brien R, Ehlers MD, Huganir RL (1999) Regulation of morphological postsynaptic silent synapses in developing hippocampal neurons. Nat Neurosci 2:37-43. CrossRef Medline

Lin CW, Sim S, Ainsworth A, Okada M, Kelsch W, Lois C (2010) Genetically increased cell-intrinsic excitability enhances neuronal integration into adult brain circuits. Neuron 65:32-39. CrossRef Medline

Livneh Y, Feinstein N, Klein M, Mizrahi A (2009) Sensory input enhances synaptogenesis of adult-born neurons. J Neurosci 29:86-97. CrossRef Medline

Lledo PM, Saghatelyan A (2005) Integrating new neurons into the adult olfactory bulb: joining the network, life-death decisions, and the effects of sensory experience. Trends Neurosci 28:248-254. CrossRef Medline

Lledo PM, Alonso M, Grubb MS (2006) Adult neurogenesis and functional plasticity in neuronal circuits. Nat Rev Neurosci 7:179-193. CrossRef Medline

Matsutani S, Yamamoto N (2008) Centrifugal innervation of the mammalian olfactory bulb. Anat Sci Int 83:218-227. CrossRef Medline

Mizrahi A (2007) Dendritic development and plasticity of adult-born neu- 
rons in the mouse olfactory bulb. Nat Neurosci 10:444-452. CrossRef Medline

Monyer H, Burnashev N, Laurie DJ, Sakmann B, Seeburg PH (1994) Developmental and regional expression in the rat brain and functional properties of four NMDA receptors. Neuron 12:529-540. CrossRef Medline

Nissant A, Bardy C, Katagiri H, Murray K, Lledo PM (2009) Adult neurogenesis promotes synaptic plasticity in the olfactory bulb. Nat Neurosci 12:728-730. CrossRef Medline

Pallotto M, Nissant A, Fritschy JM, Rudolph U, Sassoè-Pognetto M, Panzanelli P, Lledo PM (2012) Early formation of GABAergic synapses governs the development of adult-born neurons in the olfactory bulb. J Neurosci 32:9103-9115. CrossRef Medline

Panzanelli P, Bardy C, Nissant A, Pallotto M, Sassoè-Pognetto M, Lledo PM, Fritschy JM (2009) Early synapse formation in developing interneurons of the adult olfactory bulb. J Neurosci 29:15039-15052. CrossRef Medline

Petreanu L, Alvarez-Buylla A (2002) Maturation and death of adult-born olfactory bulb granule neurons: role of olfaction. J Neurosci 22:61066113. Medline

Platel JC, Dave KA, Gordon V, Lacar B, Rubio ME, Bordey A (2010) NMDA receptors activated by subventricular zone astrocytic glutamate are critical for neuroblast survival prior to entering a synaptic network. Neuron 65:859-872. CrossRef Medline

Rochefort C, Gheusi G, Vincent JD, Lledo PM (2002) Enriched odor exposure increases the number of newborn neurons in the adult olfactory bulb and improves odor memory. J Neurosci 22:2679-2689. Medline

Saghatelyan A, Roux P, Migliore M, Rochefort C, Desmaisons D, Charneau P, Shepherd GM, Lledo PM (2005) Activity-dependent adjustments of the inhibitory network in the olfactory bulb following early postnatal deprivation. Neuron 46:103-116. CrossRef Medline

Sanz-Clemente A, Nicoll RA, Roche KW (2013) Diversity in NMDA receptor composition: many regulators, many consequences. Neuroscientist 19:62-75. CrossRef Medline

Sassoè-Pognetto M, Utvik JK, Camoletto P, Watanabe M, Stephenson FA, Bredt DS, Ottersen OP (2003) Organization of postsynaptic density proteins and glutamate receptors in axodendritic and dendrodendritic synapses of the rat olfactory bulb. J Comp Neurol 463:237-248. CrossRef Medline

Shepherd GM, Chen WR, Greer CA (2004) Olfactory bulb. In: The synaptic organization of the brain. (Shepherd GM, ed), pp 165-216. New York: Oxford UP.

Tovar KR, Westbrook GL (1999) The incorporation of NMDA receptors with a distinct subunit composition at nascent hippocampal synapses in vitro. J Neurosci 19:4180-4188. Medline

Whitman MC, Greer CA (2007) Synaptic integration of adult-generated olfactory bulb granule cells: basal axodendritic centrifugal input precedes apical dendrodendritic local circuits. J Neurosci 27:9951-9961. CrossRef Medline

Yamaguchi M, Mori K (2005) Critical period for sensory experiencedependent survival of newly generated granule cells in the adult mouse olfactory bulb. Proc Natl Acad Sci U S A 102:9697-9702. CrossRef Medline

Ziv NE, Smith SJ (1996) Evidence for a role of dendritic filopodia in synaptogenesis and spine formation. Neuron 17:91-102. CrossRef Medline 